Document downloaded from:

http://hdl.handle.net/10251/79100

This paper must be cited as:

Jornet Olivé, MD.; Castillo López, MÁ; Sabater Marco, C.; Tormos Faus, RE.; Miranda Alonso, MÁ. (2013). Photodegradation of carbendazim sensitized by aromatic ketones. Journal of Photochemistry and Photobiology A: Chemistry. 256:36-41. doi:10.1016/j.jphotochem.2013.02.004.

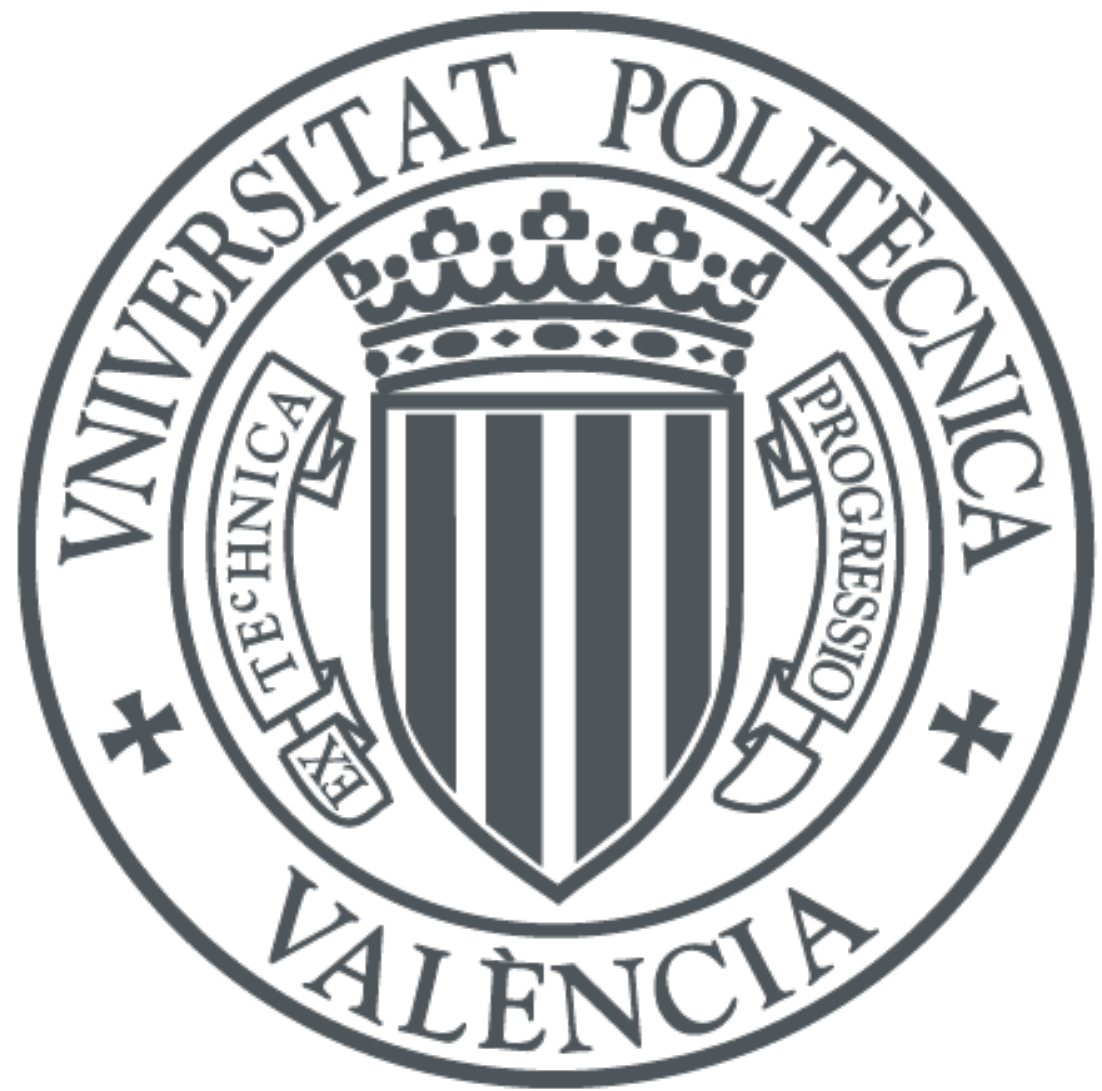

The final publication is available at

http://dx.doi.org/10.1016/j.jphotochem.2013.02.004

Copyright Elsevier

Additional Information 


\section{Highlights}

Photocatalyzed oxidation of carbendazim by aromatic ketones under solar-simulated steadystate.

Characterization of the transients generated by laser flash photolysis (LFP)

Identification of the major photoproduct of photocatalytic oxidation

Detoxification of carbendazim solutions revealed by the inhibition of mobility in the Daphnia magna assay. 


\title{
Photodegradation of carbendazim sensitized by
}

\section{aromatic ketones}

Dolors Jornet $^{\mathrm{a}}, \mathrm{M}^{\mathrm{a}}$ Angeles Castillo ${ }^{\mathrm{b}}, \mathrm{M}^{\mathrm{a}}$ Consuelo Sabater ${ }^{\mathrm{b}}$, Rosa Tormos ${ }^{\mathrm{a}^{*}}$ and Miguel A. Miranda ${ }^{a^{*}}$

${ }^{\text {a}}$ Departamento de Química/Instituto de Tecnología Química UPV-CSIC, ${ }^{\text {b }}$

Departamento de Biotecnología, Universitat Politècnica de València, Avenida de los Naranjos s/n, E-46022 Valencia, Spain

RECEIVED DATE (to be automatically inserted after your manuscript is accepted if required according to the journal that you are submitting your paper to)

Corresponding author. Address: Departamento de Química/Instituto de Tecnología Química UPV-CSIC, Universitat Politècnica de València, Avenida de los Naranjos s/n, E-46022 Valencia, Spain. Fax: +34 963877809. E-mail address: $\underline{\text { mmiranda@qim.upv.es }}$ (M. A. Miranda)

\begin{abstract}
Carbendazim (1) is a benzimidazole extensively used as post-harvest fungicide on fruits and vegetables. The aim of the present work is to study the photodegradation of $\mathbf{1}$ sensitized by aromatic ketones, with special attention to mechanistic aspects and to the possible detoxification associated with photochemical treatment. Laser flash photolysis (LPF) $\lambda_{\text {exc }}=355 \mathrm{~nm}$ of xanthone (XA) and anthraquinone (AQ) was performed in MeCN solutions, in the presence of $\mathbf{1}$. A new transient absorbing at $\lambda_{\max }$ 500 and $320 \mathrm{~nm}$ was obtained and assigned to the semioxidized radical cation $\mathbf{1}^{+\cdot}$. An exergonic thermodynamics for electron transfer quenching was confirmed by means of
\end{abstract}


the Rehm-Weller equation. The same species was observed by direct LFP of $\mathbf{1}$ at 266 $\mathrm{nm}$ in polar solvents. Conversely, when a deoxygenated solution of $\mathbf{1}$ was submitted to LFP in cyclohexane the transient spectrum presented a band with maximum at $380 \mathrm{~nm}$; it was assigned to the triplet excited state $\left({ }^{3} \mathbf{1}^{*}\right)$ on the basis of energy transfer to oxygen and $\beta$-carotene. The photodegradation of $\mathbf{1}$ was achieved using $\mathbf{X A}$ and $\mathbf{A Q}$ as electron acceptors in a solar-simulator, in aerated aqueous medium; the reaction was faster with XA. Formation of a new photoproduct was initially observed; its structure was assigned as carbendazim N-C5 dimer (2). A balance of the total organic carbon (TOC) after prolonged irradiation indicated that mineralization does not occur to a significant extent, pointing to oxidative fragmentation of $\mathbf{1}$ and $\mathbf{2}$ to give a variety of low molecular weight products. To check whether the observed photodegradation of $\mathbf{1}$ results in a decreased toxicity, biological assays were performed using an established model based on the inhibition of mobility of Daphnia magna. The results demonstrate that photodegradation leads to in a diminished toxicity, indicating that the photoproducts are less toxic than the parent compound.

\section{Introduction}

Carbendazim (1, Chart 1) is a member of the benzimidazole (BZ) family, which includes a series of heterocyclic compounds extensively used as broad spectrum anthelmintic, anti-nematodal and anti-protozoal agents, ${ }^{1-5}$ as well as post-harvest fungicides on fruits and vegetables. ${ }^{6-8}$ The extensive use of 1(12000 tons/year) and related BZs has led to the development of resistance, which is usually triggered by mutation(s) in a single chromosomal $\beta$-tubulin gene. ${ }^{9-12}$ Interestingly, this effect has been exploited for inhibition of cancer cell proliferation by suppressing microtubule dynamics. $^{13}$ 
Unfortunately, BZs are toxic to humans and animals, so in the last years increasing attention has been devoted to their elimination from the environment ${ }^{14-17}$ and to the development of methods for detection of traces in vegetables and water. ${ }^{18-30}$ The importance of the problem generated by pesticide residues, including BZs, has led to specific regulations established by the European Union $^{31}$ and by the Environmetal Protection Agency (EPA). ${ }^{32}$

A key issue in connection with the efficacy and the ecological consequences of pesticides is their persistence. For field applications, these chemicals should survive only during the period required for pest control, to minimize contamination of soils and waters. Sunlight exposure could in principle contribute to the degradation of pesticides. In general, pesticides absorb weakly solar radiation (above 290-300 $\mathrm{nm}$ ) and accordingly they are relatively photostable under natural exposure conditions. A possible way to extend the active fraction of sunlight for removal of the pesticides might be the utilization of a photosensitizer capable of absorbing longer wavelength radiation.

It is therefore surprising that, in general, little attention has been devoted to the effects of light on BZs, with the exception of a few studies focused on their environmental fate. ${ }^{33,34}$ In this context, a recent review has appeared on the oxidation of pollutans by means of organic photocatalysts, including the photodegradation of a series of substituted BZs. ${ }^{35}$

Specifically, the influence of light on the persistence of $\mathbf{1}$ has been analyzed by different autors. ${ }^{36-38}$ This compound is rather stable in the dark or under environmental illumination conditions. Conversely, when exposed to the combined action of UV light and oxygen, $\mathbf{1}$ reacts in a wavelength-, solvent-, and $\mathrm{pH}-$ dependent manner. ${ }^{39}$ Direct 
irradiation of $\mathbf{1}$ in water affords 2-aminobenzimidazole as major photoproduct, via photohydrolysis, together with other minor products arising from electron photoejection accompanied by breakdown of the imidazole ring. ${ }^{40,41}$ The reaction of $\mathbf{1}$ with photogenerated hydroxyl radicals affords mainly photoproducts hydroxylated in the benzene ring. ${ }^{39}$ As regards the photophysical characterization of $\mathbf{1}$, the emission spectrum has been registered, and the energies of the first singlet $\left(S_{1}\right)$ and triplet $\left(T_{1}\right)$ excited states have been determined as 99.7 and $79.7 \mathrm{kcal} \mathrm{mol}^{-1}$ respectively. ${ }^{41}$ Moreover, 1 has been included in confined media looking for an emission enhancement to improve its analytical detection ${ }^{42-44}$ and, more importantly, to increase its solubility and bioavailability. ${ }^{45,46}$ However, the behavior of the triplet excited state and other possible transients generated from $\mathbf{1}$ have not been investigated as yet. With this background, the aim of the present work is to study the photodegradation of carbendazim sensitized by aromatic ketones, under solar-simulated steady-state irradiation, with special attention to mechanistic aspects as revealed by the full characterization of the transients generated by laser flash photolysis (LFP) and to the identification of the major photoproduct(s). In addition, the possible detoxification of irradiated carbendazim solutions has been evaluated by an established model based on the inhibition of mobility of Daphnia magna.

\section{Experimental}

\subsection{Materials and Solvents}

Carbendazim (1), xanthone (XA), benzophenone (BP), 9,10-anthraquinone (AQ), 2hydroxybenzimidazole, tert-butylperoxide, $S$-flurbiprofen and triphenylpyrylium tetrafluoroborate (TPT) were purchased from Aldrich. Their purity was checked by ${ }^{1} \mathrm{H}$ nuclear magnetic resonance (NMR) spectroscopy and high performance liquid 
chromatography (HPLC) analysis. Reagent grade solvents acetonitrile, cyclohexane, and methanol were purchased from Scharlau and used without further purification.

\subsection{Absorption and Emission Spectra}

Optical spectra in different solvents were measured on a Jasco V-630 spectrophotometer. Emission spectra were recorded on a spectrofluorometer system Jasco FP-8500, provided with an M 300 emission monochromator in the wavelength range of 200-900 nm and are uncorrected. Samples were placed into $10 \times 10 \mathrm{~mm}^{2}$ Suprasil quartz cells with a septum cap. Solutions were purged with nitrogen or oxygen for at least $10 \mathrm{~min}$ before the measurements. Fluorescence quantum yields were determined using $S$-flurbiprofen $\quad[S$-2-fluoro- $\alpha$-methyl-4-biphenylacetic acid] as reference $\left(\Phi_{\mathrm{F}}=0.27\right.$ at $\lambda_{\mathrm{exc}}=281 \mathrm{~nm}$ in methanol $){ }^{47}$ The absorbance of the samples at the excitation wavelength was kept below 0.1. Excitation and emission slits were maintained unchanged during the emission experiments. For time-resolved fluorescence decay measurements, the conventional single photon counting was used. All experiments were performed at room temperature $\left(22^{\circ} \mathrm{C}\right)$.

\subsection{Laser Flash Photolysis Experiments}

The LFP experiments were carried out by using a Q-switched Nd:YAG laser (Quantel Brilliant, 266 or $355 \mathrm{~nm}, 10$ or $14 \mathrm{~mJ}$ per pulse, $5 \mathrm{~ns}$ fwhm) coupled to a mLFP111 Luzchem miniaturized equipment. This transient absorption spectrometer includes a ceramic xenon light source, $125 \mathrm{~mm}$ monochromator, Tektronix 9-bit digitizer TDS-3000 series with $300 \mathrm{MHz}$ bandwith, compact photomultiplier and power supply, cell holder and fiber optic connectors, fiber optic sensor for laser-sensing pretrigger signal, computer interfaces and a software package developed in the LabVIEW environment from National 
Instruments. The LFP equipment supplies $5 \mathrm{~V}$ trigger pulses with programmable frequency and delay. The risetime of the detector/digitizer is approximately $3 \mathrm{~ns}$ up to $300 \mathrm{MHz}$ (2.5 $\mathrm{GHz}$ sampling). The laser pulse is probed by a fiber that synchronizes the LFP system with the digitizer operating in the pretrigger mode. All transient spectra were recorded using 10 x $10 \mathrm{~mm}^{2}$ quartz cells with $4 \mathrm{~mL}$ capacity, and all were bubbled during 20 min with $\mathrm{N}_{2}$. Absorbance of the samples was kept between 0.2 and 0.3 at the laser wavelength. All the experiments were carried out at room temperature.

\subsection{Irradiation Procedures}

Aerated aqueous solutions of $\mathbf{1}\left(4.2 \times 10^{-4} \mathrm{M}\right)$ in the presence or absence of XA were irradiated at $\mathrm{pH}=6.5$ in a solar simulator (ABET Technologies Sun 2000). The course of the photoreaction was monitored by means of analytical HPLC, using reverse phase C18 column and methanol-water (50:50, v/v) with $0.6 \%$ of ammonia as eluent. The flow rate was $0.8 \mathrm{~mL} / \mathrm{min}$, and the detector was a photo diode array (PDA). In addition, the total organic carbon (TOC) was determined for the irradiations in aqueous medium by means of the Shimadzu model TOC-V CSH.

For isolation of photoproducts, aerated solutions of 1 in $16 \%$ aqueous acetonitrile $\left(5.2 \times 10^{-4} \mathrm{M}\right)$ were submitted to irradiation in the presence of BP, XA or AQ (5.2 x $10^{-}$ ${ }^{4}$ M) using a multilamp photoreactor equipped with 8 Hitachi FL8BL-B lamps (emission maximum $350 \mathrm{~nm}$, Gaussian distribution), through a pyrex filter. Purification was done by means of isocratic HPLC with a semipreparative column, using methanolwater $(50: 50, \mathrm{v} / \mathrm{v})$ with $0.6 \%$ of ammonia as eluent. The photoproduct was fully characterized by its ${ }^{1} \mathrm{H}$ NMR spectrum, which was registered in dimethyl sulfoxide- $\mathrm{d}_{6}$, at $400 \mathrm{MHz}$. The chemical shifts are reported in $\delta(\mathrm{ppm})$ values, using tetramethylsilane (TMS) as internal standard. 
Photoproduct 2, carbendazim N-C5 dimer: ${ }^{1} \mathrm{H}$ NMR $\left(\mathrm{CD}_{3}\right)_{2} \mathrm{SO}, \delta(\mathrm{ppm}): 3.72$ (s, 3H), $3.75(\mathrm{~s}, 3 \mathrm{H}), 7.07\left(\mathrm{dd}, 1 \mathrm{H}, \mathrm{J}_{1}=8.4 \mathrm{~Hz}, \mathrm{~J}_{2}=1.6 \mathrm{~Hz}\right), 7.09(\mathrm{~m}, 1 \mathrm{H}), 7.13(\mathrm{~m}, 1 \mathrm{H}), 7.36(\mathrm{~d}$, $1 \mathrm{H}, \mathrm{J}=8 \mathrm{~Hz}), 7.39(\mathrm{~d}, 1 \mathrm{H}, \mathrm{J}=1.6 \mathrm{~Hz}), 7.41(\mathrm{~d}, 1 \mathrm{H}, \mathrm{J}=8.4 \mathrm{~Hz}), 7.47(\mathrm{~d}, 1 \mathrm{H}, \mathrm{J}=8$ Hz). HRMS calcd for $\left[\mathrm{C}_{18} \mathrm{H}_{17} \mathrm{~N}_{6} \mathrm{O}_{4}\right][\mathrm{M}+1]^{+}: 381.1296$, found: 381.1311

\subsection{Toxicity Assays}

The ephippia (dormant eggs) of crustacean Daphnia. magna were supplied by ECOtest S.L. (Valencia, Spain). The toxicity assays were performed assessing the inhibition of the mobility of D. magna according to the standard ISO $6341: 1996^{48}$ procedure. The bioassay uses 24 -h old daphnids hatched from the ephippia. Five neonates were placed in $15 \mathrm{~mL}$ appropriate containers with $10 \mathrm{~mL}$ of test dilution. The assays were conducted in the dark at a constant temperature of $21 \pm 1^{\circ} \mathrm{C}$. At the end of the test period (24 h) mobile D. magna were counted in each container. Those unable to swim in the $15 \mathrm{~s}$ after agitation were considered immobile. All experiments were done in quadruplicate.

Different dilutions were prepared with the standard freshwater, according to mentioned guideline. Standard freshwater was also used as hatching medium. Assays were conducted with a range of test dilutions in geometric progression plus the controls. Whenever possible, data were used to calculate the $\mathrm{EC}_{50}$ (sample dilution required to immobilize $50 \%$ of the daphnids after $24 \mathrm{~h}$ exposure) by Probit analysis, using the Statistical Analysis System SPSS (version 16.0). Toxicity data were analyzed with oneway analysis of variance (ANOVA) to inspect the effect of treatment time (4, 24 and 48 h). The Fisher's least significant difference (LSD) test was used to determine which treatments are statistically significant with respect to the untreated sample. A $P<0.05$ was taken to indicate statistical significance (STATGRAPHICS PLUS version 5.1). 


\section{Results and Discussion}

\subsection{Photophysical studies}

The absorption spectra of $\mathbf{1}$ in different solvents are shown in Figure 1A. In acetonitrile, methanol and water they displayed two bands, with maxima $c a .290$ and $245 \mathrm{~nm}$. In cyclohexane solution, only one broad band with maximum at $275 \mathrm{~nm}$ and a shoulder at $295 \mathrm{~nm}$ was observed.

The fluorescence spectra of $\mathbf{1}$ were also registered in the same solvents (Figure 1B); in all cases the emission maximum was found at $305 \mathrm{~nm}$. The excitation spectrum shows a maximum at $284 \mathrm{~nm}$.

The fluorescence quantum yield was measured in the above solvents, and the values were found to be 0.044 in methanol, 0.073 in acetonitrile, 0.037 in cyclohexane and 0.015 in water. This is in reasonable agreement with the reported value of $c a 1.10^{-2}$ in diluted aqueous solutions. ${ }^{40}$ The singlet lifetime was in all cases shorter than $1 \mathrm{~ns}$, the detection limit of the apparatus.

Laser flash photolysis $\left(\lambda_{\mathrm{exc}}=355 \mathrm{~nm}\right)$ of xanthone $(\mathbf{X A})$, anthraquinone $(\mathbf{A Q})$ and benzophenone (BP) was performed in $\mathrm{MeCN}$ solutions, in the presence of $\mathbf{1}$. Under these conditions, triplet-triplet energy transfer is prevented, due to the relative excited state energies, which are higher for $\mathbf{1}\left(79 \mathrm{kcal} \mathrm{mol}^{-1}\right)$ than for the ketones (see Table 1). ${ }^{38,49}$ Transients absorbing in the $300-570 \mathrm{~nm}$ range were obtained upon quenching of XA or AQ with 1, but no new signal was detected in the case of BP. Figure 2 shows deactivation of the $\mathbf{X A}$ and $\mathbf{A Q}$ triplets in the presence of $\mathbf{1}$, with the concomitant formation of new transients peaking at 500 and $320 \mathrm{~nm}$, which decayed with the same kinetics $(\tau=165 \mu \mathrm{s})$ 
In principle a radical ion pair $\mathbf{1}^{+*} / \mathbf{X A}^{*^{-}}$or $\mathbf{1}^{+*} / \mathbf{A} \mathbf{Q}^{*}$ could be generated by electron transfer from 1 to the ketones. ${ }^{50}$ Subsequent proton transfer within the radical ion pair would produce radical $\mathbf{1 - H} \cdot$ together with $\mathbf{X A H} \cdot$ or AQH• Thus, the transient with bands at 320 and $500 \mathrm{~nm}$ could correspond to the semioxidized species $\mathbf{1}^{+\cdot}$ or $\mathbf{1 - H} \cdot$; unfortunately the absorptions of the semireduced species $\mathbf{X A} \mathbf{A}^{-} / \mathbf{X A H} \cdot$ or $\mathbf{A Q} \mathbf{Q}^{\bullet}$ / AQH ${ }^{51-55}$ are too weak and/or overlap with the strong absorptions attributed to $\mathbf{1}^{+\bullet} / \mathbf{1 -}$ $\mathbf{H} \cdot$, so their clearcut detection by LFP was not possible.

The energetics of radical ion pair formation through electron transfer (et) can be estimated with equation $(1)^{56}$

$$
\Delta \mathrm{G}_{\mathrm{et}}=23.06\left(\mathrm{E}_{\mathrm{ox}}-\mathrm{E}_{\mathrm{red}}\right)-\mathrm{E}^{*}(1)
$$

where $E_{o x}$ is the oxidation potential of the donor $(\mathbf{1}),{ }^{57} E_{\text {red }}$ the reduction potential of the aromatic ketone acceptor and $\mathrm{E}^{*}$ is the triplet energy of the ketone. ${ }^{58}$ In this way, using the values given in Table 1 for the above mentioned parameters exergonic thermodynamics for electron transfer quenching of the triplet-state of $\mathbf{X A}$ and $\mathbf{A Q}$ was established in acetonitrile. By contrast, the process was found to be endergonic for $\mathbf{B P}$ (Table 1).

In order to ascertain the nature of the observed transient, an alternative approach to generate both $\mathbf{1}^{+\cdot}$ and $\mathbf{1 - H} \cdot$ was used. A solution of $\mathbf{1}$ in a mixture of acetonitrile and tert-butylperoxide $(10: 1, \mathrm{v} / \mathrm{v})$ was irradiated at $355 \mathrm{~nm}$. Under these conditions the generated tert-butoxy radical $(\mathbf{R O} \cdot)$ should abstract hydrogen from $\mathbf{1}$, leading to formation of tert-butanol and $\mathbf{1 - H} \cdot$ radical. ${ }^{59}$ However, no new signal attributable to a radical was detected.

Additionally, triphenylpyrylium tetrafluoroborate (TPT) was selected as oxidizing photosensitizer without proton accepting capability. ${ }^{60}$ Thus TPT was irradiated in acetonitrile solution alone and in the presence of $\mathbf{1}$. The shapes of the obtained spectra were similar, due to partial overlap of the transient signals; however, the decays were longer in the presence of $\mathbf{1}$. The spectrum resulting from subtraction of 
the traces obtained upon photolysis of TPT in the absence and presence of $\mathbf{1}$ displays a band centered at $500 \mathrm{~nm}$ that can be reasonably attributed to the absorption of $\mathbf{1}^{++}$ (Figure3, inset).

For mechanistic insight and to clarify the nature of the intermediates involved in the direct UV-irradiation of $\mathbf{1},{ }^{37} \mathrm{LFP}$ of $\mathbf{1}$ at $266 \mathrm{~nm}$ in different polar solvents $(\mathrm{MeOH}$, $\mathrm{MeCN}, \mathrm{H}_{2} \mathrm{O}$ ) was performed. Interestingly, in deaerated acetonitrile transients absorbing at 320 and $500 \mathrm{~nm}$ were detected (Figure 3), wich were very similar to those obtained by photosensitization with ketones. The lifetime was very long in all solvents $\left(\tau_{\mathrm{MeOH}}=154 \mu \mathrm{s}, \tau_{\mathrm{MeCN}}=165 \mu \mathrm{s}\right.$, and $\left.\tau_{\mathrm{H} 2 \mathrm{O}}=146 \mu \mathrm{s}\right)$. Both bands decayed with the same kinetics, and their quenching by oxygen was very slow $\left(\mathrm{k}_{\mathrm{q}}=6.8 \times 10^{5} \mathrm{M}^{-1} \mathrm{~s}^{-1}\right)$.

To disclose whether the generated radical cation ${\mathbf{1}^{+}}^{+}$was the result of a monophotonic or a biphotonic process, 1 was submitted to LFP with laser pulses of increasing energy from 5.7 to $16.4 \mathrm{~mJ}$. As shown in Figure 3 inset, the variation of the end-of-pulse absorbance at $500 \mathrm{~nm}$ with the laser energy fits well with a linear plot; this indicates that the photoionization is a monophotonic process.

Finally, a deoxygenated solution of $\mathbf{1}$ was submitted to LFP in an apolar solvent such as cyclohexane, where formation of a radical cation is prevented. Under these conditions, the registered transient spectrum presented a band with maximum at $380 \mathrm{~nm}$ and a lifetime of $1.7 \mu \mathrm{s}$.

Under oxygen atmosphere the signal was quenched $\left(\mathrm{k}_{\mathrm{q}}=1.53 \times 10^{10} \mathrm{M}^{-1} \mathrm{~s}^{-1}\right)$, pointing to triplet formation. To confirm this assignment $\beta$-carotene was added; the $380 \mathrm{~nm}$ signal was quenched concomitantly with the growth of a signal at $520 \mathrm{~nm}$ (Figure 4 inset); safely ascribed to $\beta$-carotene triplet-triplet absorption. ${ }^{49}$

\subsection{Photodegradation}


The photodegradation of $\mathbf{1}$ was attempted using $\mathbf{A Q}, \mathbf{X A}$ and $\mathbf{B P}$ as electron acceptors. Photolysis was performed in a solar-simulator, in aerated aqueous medium. The photoreaction was monitored by HPLC, with a PDA detector using 2hydroxybenzimidazole as internal standard (IS). Under the employed analytical conditions, $\mathbf{1}$ appeared at a retention time (Rt) of 9.31 minutes while the ketones eluted later (Figure 5A). The chromatogram obtained after irradiation of a XA/1 mixture showed the appearance of a new peak with Rt of 12 minutes and with an absorption spectrum very similar to that of $\mathbf{1}$, together with small amounts of unidentified byproducts. The reaction was slower with $\mathbf{A Q}$, while little if any conversion was observed with BP. Interestingly, in the absence of any photosensitizer, under otherwise identical experimental conditions, compound 1 was found to be nearly photostable. Figure 5B shows the kinetics of disappearance of $\mathbf{1}$, together with formation of a photoproduct. Its structure was assigned as carbendazim N-C5 dimer (2) after isolation by semipreparative HPLC and spectroscopic characterization by means of HRMS and ${ }^{1} \mathrm{H}$ NMR (Chart 2).

The concentration of carbendazim decreased concomitantly with the increasing concentration of $\mathbf{2}$, which reached a maximum. At this stage, the absorbance of $\mathbf{2}$ was nearly a half of that initially presented by $\mathbf{1}$ in spite of the fact that both compounds contain very similar chromophores. In principle, this could be attributed to partial mineralization of the organic material or to oxidative fragmentation to give a variety of low molecular weight products. A balance of the total organic carbon (TOC), at the beginning and at the end of the reaction indicated that mineralization does not occur to a significant extent.

To check whether the observed photodegradation of $\mathbf{1}$ results in a decreased toxicity, biological assays with Daphnia magna as model system were performed. The 
results (Figure 6) are expressed as percentages of immobilization of daphnids exposed to serial dilutions of samples, treated during different times.

At 1:1 dilution the samples exhibited a high toxicity (100\% immobilization) after $24 \mathrm{~h}$ treatment. Only after $48 \mathrm{~h}$ of treatment, a decreased toxicity (60\%) was observed. For all other samples, the toxicity decreased with increasing dilutions and treatment times.

Estimation of the concentration causing 50\% immobilization $\left(\mathrm{EC}_{50}\right)$ and corresponding 95\% confidence limits, calculated with Probit analysis, indicated a good fit for samples derived of $24 \mathrm{~h}$ treatment $\left(\chi^{2}=28.95, p=0.146\right)$, which corresponded to 1:2 dilution with 1:3-1:1.5 dilutions as $95 \%$ confidence limits.

These results demonstrate that photosensitized degradation results in a diminished toxicity, indicating that the photoproducts are less toxic than the parent compound 1.

\section{Conclusion}

Irradiation of aerated aqueous solutions of carbendazim photosensitized with xanthone or anthraquinone, using simulated sunlight, leads to efficient photodegradation. The primary photoproduct is a N-C5 dimer. The reaction mechanism involves electron transfer from carbendazim to the triplet excited state of the aromatic ketones; this is supported by detection of the key transients by means of laser flash photolysis. This process results in substantial detoxification, as revealed by the inhibition of mobility in the Daphnia magna assay.

\section{Acknowledgment.}

Financial support from the MICINN (Grant: CTQ2010-19909) and the Generalitat Valenciana (Prometeo Program) is gratefully acknowledged. 


\section{References and notes}

[1] J. M. Behnke, D. J. Buttle, G. Stepek, A. Lowe, I. R Duce, ParasitesVectors (2008) 1 .

[2] R.K. Prichard, Parasitology 134 (2007) 1087.

[3] R. K. Prichard, G. von Samson-Himmelstjerna, W. J. Blackhall, T. G. Geary, Parasitology 134 (2007)1073.

[4] G.von Samson-Himmelstjerna, W. J. Blackhall, J. S. McCarthy, P. J. Skuce, Parasitology 134 (2007) 1077.

[5] M. Bossche van de, D. Thienpoint, P.G. Janssens, Chemotherapy of Gastrointestinal Helminths, Springer, Berlin (1985)

[6] H. Das, S. Jayaraman, M. Naika, A. S. Bawa, J. Food Sci. Technol. 44 (2007) 237.

[7] S. Tahara, J. L. Ingham, Stud. Nat. Prod. Chem. 22 (Bioactive Natural Products Part C) (2000) 457.

[8] L. C. Davidse, Ann. Rev. of Phytopathology 24 (1986) 43.

[9] Y. Hou, Q. Luo, C. Chen, M. Zhou, Pest Management Sci. 67 (2011) 1124.

[10] J. B. Qiu, J. Q. Xu, J. J. Yu, C. W. Bi, C. J. Chen, M. G. Zhou, Pest Management Sci. 67 (2011) 191.

[11] C. Chen, J-J. Yu, C-W. Bi, Y-N. Zhang, J-Q. Xu, J-X. Wang, M.-G. Zhou, Phytopathology 99 ( 2009) 1403.

[12] B. N. Ziogas, D. Nikou, A. N. Markoglou, A. A. Malandrakis, J. Vontas, Eur. J. Plant Pathol. 125 (2009) 97.

[13] M. Yenjerla, C. Cox, L. Wilson, M. A. Jordan, J. Pharmacol. Exp. Ther 328 (2009) 390.

[14] A. Bojanowska-Czajka, H. Nichipor, P. Drzewicz, B. Szostek, A. Galezowska, S. Meczynska, M. Kruszewski, Z. Zimek, G. Nalecz-Jawecki, M. Trojanowicz, J. Radioanal. Nuclear Chem. 289 (2011) 303. 
[15] A. Rico, A.V. Waichman, R. Geber-Correa, P. J. den Brink, Ecotoxicology 20 (2011) 625 .

[16] I. Soares De Melo, C. M. Silva, S. Maganhotto De, J. L. Faull, Pesticidas 20 (2010) 1.

[17] H. Nagase, A. Pattanasupong, E. Sugimoto, K. Tani, M. Nasu, K. Hirata, K. Miyamoto, Biochem. Eng. J. 29 (2006) 163.

[18] J. L. Flores, M.L. Fernandez de Cordova, A. M. Diaz, Anal. Sci. 25 (2009) 681.

[19] N. Egashira, Y. Mitoma, K. Shimizu, T. Uda, Chem. Sensors 20 (Suppl. B) (2004) 628.

[20] P. Calza, S. Baudino, R. Aigotti, C. Baiocchi, E. Pelizzetti, J. Chromatogr. A 984 (2003) 59.

[21] E. Hogendoorn, P. van Zoonen, J. Chromatogr. A 892 (2000) 435.

[22] G. R van der Hoff, P. van Zoonen, J. Chromatogr. A 843 (1999) 301.

[23] A. Amirav, H. Jing, J. Chromatogr. A 814 (1998) 133.

[24] F. Ozturk Akbal, N. Akdemir, A. Nur Onar, Talanta 53 (2000) 131.

[25] E. Mallat, D. Barcelo, C. Barzen, G. Gauglitz, R. Abukbessha, Trends Anal. Chem. 20 (2001) 124.

[26] P. Manisankar, G. Selvanathan, C. Vedhi, Talanta 68 (2006) 686.

[27] B. Gilbert-Lopez, J. F. Garcia-Reyes, M. Mezcua, N. Ramos-Martos, A. R. Fernandez-Alba, A. Molina-Diaz, Talanta 81 (2010) 1310.

[28] L. Burel-Deschamps, P. Giamarchi, L. Stephan, Y. Lijour, A. Bihan, J. Fluoresc. 16 (2006) 177.

[29] B. Kmellar, L. Abranko, P. Fodor, S. J. Lehotay, Food Additives \& Contaminants, Part A: Chemistry, Analysis, Control, Exposure \& Risk Assessment 27 (2010) 1415. 
[30] W. F. Ribeiro, T. M. G. Selva, I. C. Lopes, E. C. S. Coelho, S.G. Lemos, F. Caxico de Abreu, V. B. do Nascimento, M. C. Ugulino de Araujo, Anal. Methods 3 (2011) 1202.

[31] Pesticide EU-MRLs Database, http://ec.europa.eu/atoz_en.htm

[32] US EPA, Pesticides: Health and Safety, 2007, http://www.epa.gov/pesticides/ food/risks.htm.

[33] A. Kiss, D. Virag, J. Environ. Qual. 38 (2009) 157.

[34] V. Sarria, S. Parra, M. Invernizzi, P. Peringer, C. Pulgarin Water Sci. Technol. 44 (2000) 93.

[35] M. L. Marin, L. Santos-Juanes, A. Arques, A. M. Amat, M. A. Miranda, Chem. Rev. 112 (2012) 1710.

[36] J. P. Escalada, A. Pajares, J. Gianotti, W. A. Massad, S. Bertolotti, F. AmatGuerri, N. A. Garcia, Chemosphere 65 (2006) 237.

[37] R. Panades, A. Ibarz, S. Esplugas, Wat. Res. 34 (2000) 2951.

[38] P. Mazellier, E.Leroy, J. De Laat, B. Legube, Environ Chem. Lett. 1 (2003) 68.

[39] P. Mazellier, E. Leroy, J. De Laat, B. Legube, New J. Chem. 26 (2002) 1784.

[40] P. Mazellier, E. Leroy, B. Legube, J. Photochem. Photobiol. A: 153 (2002) 221. [41] A. Boudina, C. Emmelin, A. Baaliouamer, M. F Grenier-Loustalot, J. M. Chovelon, Chemosphere 50 (2003) 649.

[42] R.M. Maggio, G. N. Piccirilli, G. M. Escandar, Applied Spectrosc. 59 (2005) 873.

[43] M. Lezcano, W. Al-Soufi, M. Novo, E. Rodriguez-Núñez, J. Vázquez Tato, J. Agric. Food Chem. 50 (2002) 108.

[44] N. L. Pacioni, V. N. Sueldo Occello, M. Lazzarotto, A. V. Veglia, Anal. Chim. Acta 624 (2008) 13. 
[45] Ch. M. Buchanan, N. L. Buchanan, J. L. Lambert, U.S. Pat. Appl. Publ.(2007), US 20070082870 A1 20070412.

[46] S.H. Yalkowsky, PCT Int. Appl. (2003) WO 2003082273 A1 20031009.

[47] M.C. Jiménez, M.A. Miranda, R. Tormos, I. Vayá, Photochem. Photobiol. Sci. 3 (2004) 1038.

[48] Water quality- determination of the inhibition of the mobility of Daphnia magna straus (Cladocera, Crustacea)- acute toxicity test. ISO 6341:1996.

[49] Murov, S.L.; Carmichael, I.; Hug, G.L.; Handbook of Photochemistry, Marcel Dekker, Inc.; New York, $2^{\text {nd }}$ edn. (1993).

[50] D. Jornet, P. Bartovský, L. R. Domingo, R. Tormos, M. A. Miranda, J. Phys. Chem. B 114 (2010) 11920.

[51] M. Goez, B. H. M. Hussein, Phys. Chem. Chem. Phys. 6 (2004) 5490.

[52] N. Hoffmann, H. Görner, Chem. Phys. Lett. 383 (2004) 451.

[53] A. Garner, F. Wilkinson, J. Chem Soc. Faraday Trans.2 72 (1976) 1010.

[54] M. Sakamoto, X. Cai, M. Fujitsuka, T. Majima, J. Phys. Chem. 109 (2005) 6830.

[55] A. Bose, S. Basu, J. Luminisc. 129 (2009) 1385.

[56] D. Rehm, A. Weller, Isr. J. Chem. (1970) 259.

[57] P. Manisankar, G. Selvanathan, C. Vedhi, Talanta 68 (2006) 686.

[58] C. Högemann, E. Vauthey, J. Phys. Chem. A 102 (1998) 10051.

[59] H. Paul, R. D. Small, J.C. Scaiano, J. Am. Chem. Soc. 100 (1978) 4520.

[60] M.A. Miranda, H. Garcia, Chem. Rev. 94 (1994) 1063. 
Table 1

Free energy changes for the intermolecular electron transfer from $\mathbf{1}$ to excited BP, XA or AQ in acetonitrile, using the Rehm-Weller relationships.

\begin{tabular}{lccc}
\hline & $\mathrm{E}_{\text {red }}(\mathrm{V})$ & $\mathrm{E}_{\mathrm{T}}\left(\mathrm{kcal} \mathrm{mol}^{-1}\right)$ & $\Delta \mathrm{G}_{\mathrm{et}}\left(\mathrm{kcal} \mathrm{mol}^{-1}\right)^{\mathrm{a}}$ \\
\hline BP & -1.73 & 69.0 & 5.2 \\
AQ & -1.65 & 74.0 & -3.6 \\
XA & -0.94 & 62.0 & -8.0 \\
\hline
\end{tabular}

${ }^{\mathrm{a}} \mathrm{E}_{\mathrm{ox}}(\mathbf{1}): 1.4 \mathrm{~V}$ 

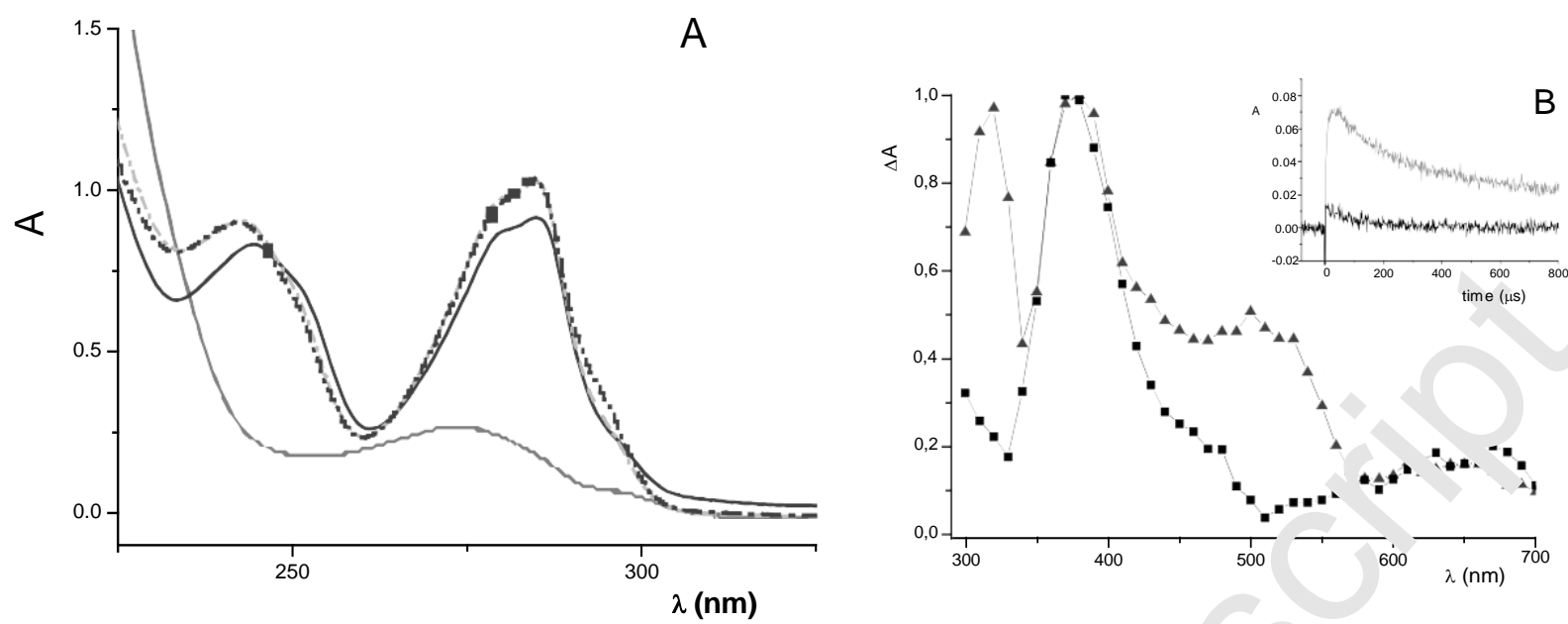

Fig. 1. (A) Transient absorption spectra obtained by $355 \mathrm{~nm}$ laser irradiation of XA solutions in $\operatorname{MeCN}(\bullet)$ alone and in the presence of $\mathbf{1}(\bullet)$ ratio $1: 1$ and $(\Delta)$ ratio 1:2, registered at $1.25 \mu \mathrm{s}$ delay times. Inset: Stern-Volmer plot obtained for triplet quenching of XA by $\mathbf{1}$ in MeCN. (B) Transient absorption spectra obtained after $355 \mathrm{~nm}$ laser irradiation of $\mathbf{A Q}$ alone $(\square)$ and in the presence of $\mathbf{1}(\boldsymbol{\Delta})$ ratio 1:3, registered at $1.25 \mu$ s delay time. Inset: kinetic traces registered at $320 \mathrm{~nm}$ for $\mathbf{A Q}$ in $\mathrm{MeCN}$ alone (-) and in the presence of $\mathbf{1}$ (ratio 1:3) 

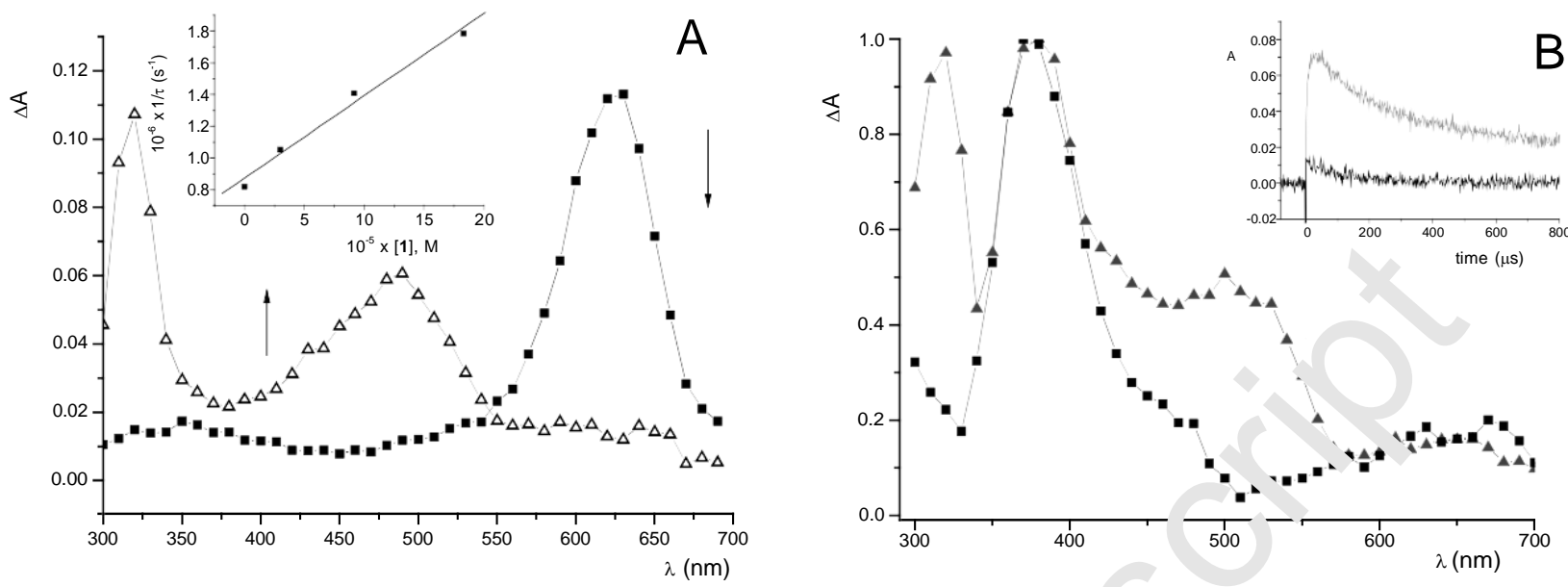

Fig. 2. (A) Transient absorption spectra obtained by $355 \mathrm{~nm}$ laser irradiation of XA solutions in $\operatorname{MeCN}(\boldsymbol{\bullet})$ alone and in the presence of $\mathbf{1}(\bullet)$ ratio $1: 1$ and $(\Delta)$ ratio 1:2, registered at $1.25 \mu \mathrm{s}$ delay times. Inset: Stern-Volmer plot obtained for triplet quenching of XA by $\mathbf{1}$ in MeCN. (B) Transient absorption spectra obtained after $355 \mathrm{~nm}$ laser irradiation of $\mathbf{A Q}$ alone $(\boldsymbol{\square})$ and in the presence of $\mathbf{1}(\boldsymbol{\Delta})$ ratio 1:3, registered at $1.25 \mu$ s delay time. Inset: kinetic traces registered at $320 \mathrm{~nm}$ for $\mathbf{A Q}$ in $\mathrm{MeCN}$ alone (-) and in the presence of $\mathbf{1}$ (ratio 1:3) 


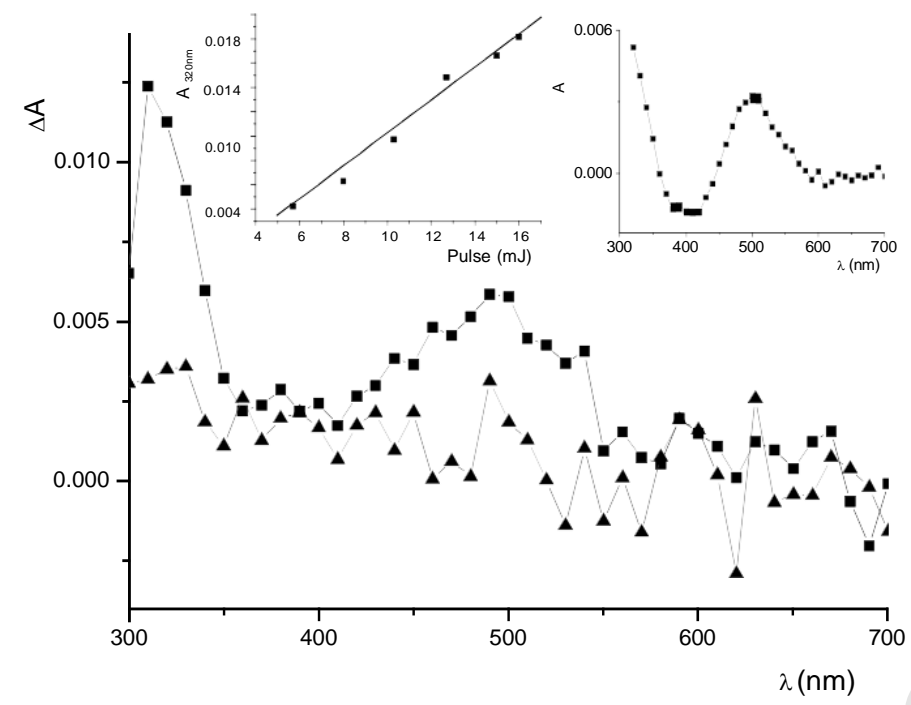

Fig. 3. Transient absorption spectra of carbendazim $\left(4.0 \times 10^{-3} \mathrm{M}\right)$ in acetonitrile after 266 $\mathrm{nm}$ irradiation, registered at $2.0 \mu \mathrm{s}(\boldsymbol{\square})$ and $364.4 \mu \mathrm{s}(\boldsymbol{\Delta})$ delay times. Insets: Plot of initial absorbance at $500 \mathrm{~nm}$ versus laser energy and spectrum resulting from subtraction of the traces upon photolysis of TPT in the presence and absence of $\mathbf{1}$. 


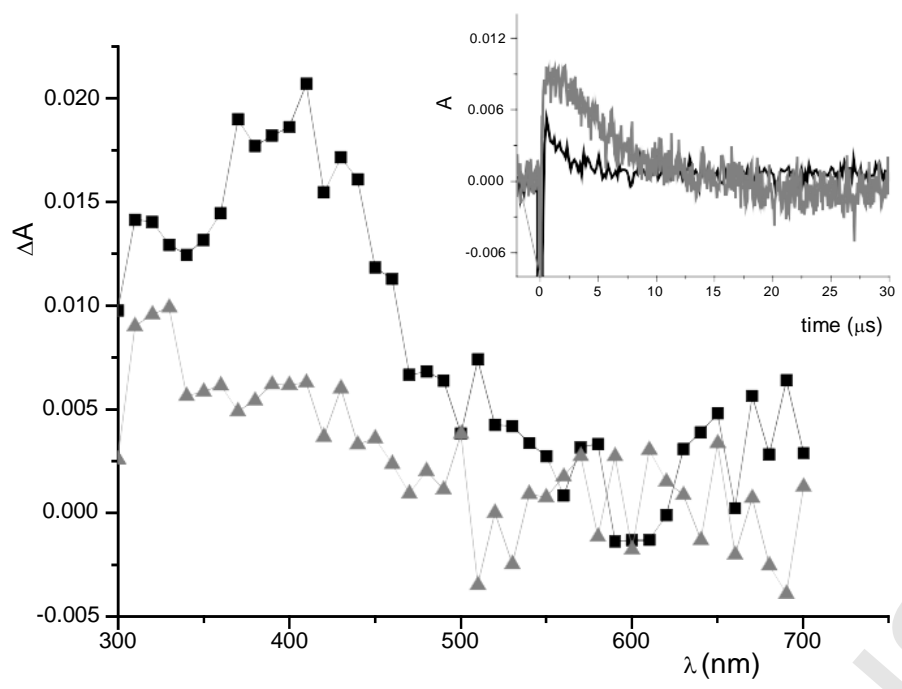

Fig. 4. Transient absorption spectra of carbendazim in saturated cyclohexane solution after 266 $\mathrm{nm}$ irradiation, registered at $0.99 \mu \mathrm{s}(\boldsymbol{-})$ and $13.41 \mu \mathrm{s}(\boldsymbol{\Delta})$ delay times. Inset: Growth (-) and decay (-) monitored, at $520 \mathrm{~nm}$ and $380 \mathrm{~nm}$ respectively, in a solution of 1 in the presence of $\beta$-carotene. 

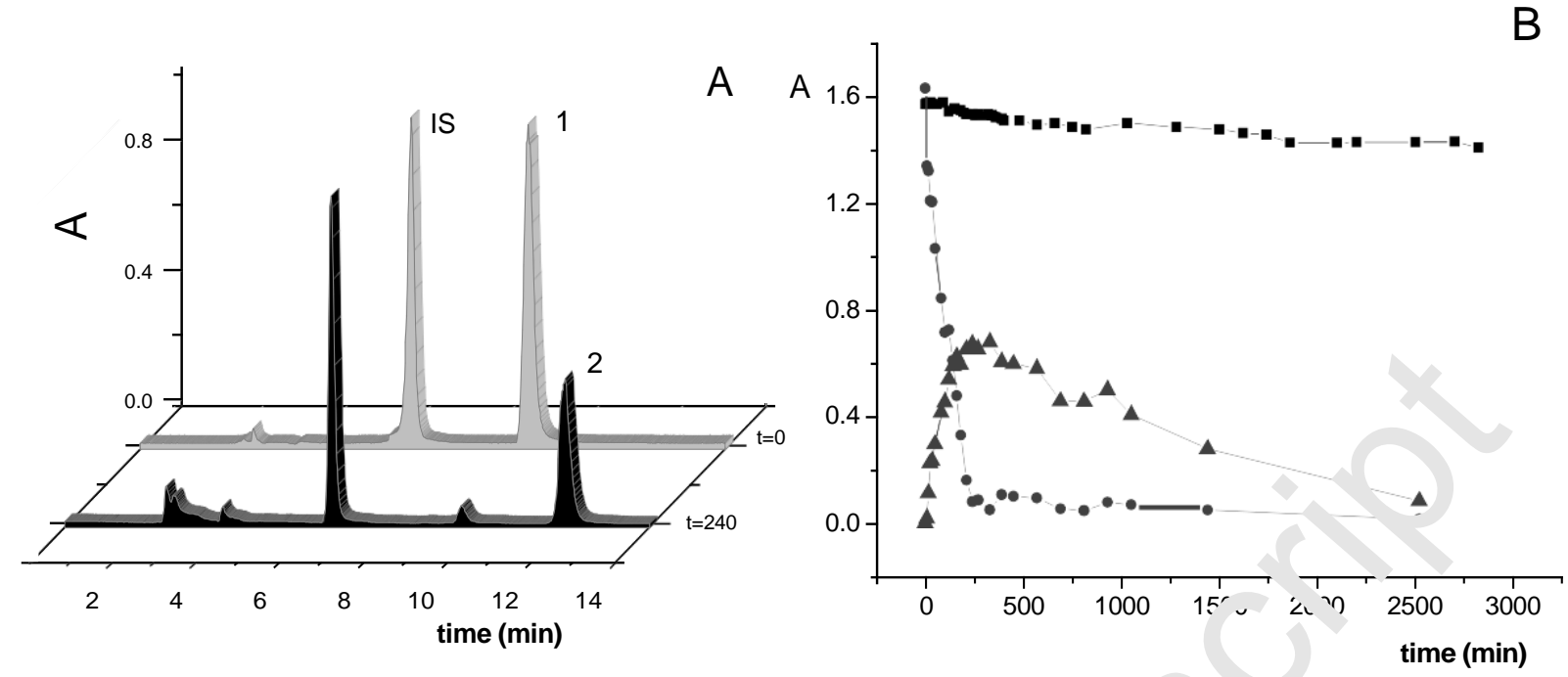

Fig. 5. (A). HPLC chromatograms recorded after irradiation of $\mathbf{1}$ in aqueous medium with a solar simulator in the presence of $\mathbf{X A}$ at $\mathrm{t}=0 \mathrm{~min}$ and at $\mathrm{t}=240 \mathrm{~min}$. The notation IS means internal standard (2-hydroxybenzimidazole) (B). Absorbance changes (measured at $280 \mathrm{~nm}$ ) versus irradiation time in the absence $(\boldsymbol{\bullet})$ and in the presence of $\mathbf{X A}(\bullet)$ measured at $\mathrm{Rt}=$ $9.31 \mathrm{~min}(\bullet$ decrease of $\mathbf{1})$ and at $\mathrm{Rt}=12 \min (\boldsymbol{\Delta}$ formation of $\mathbf{2})$ 


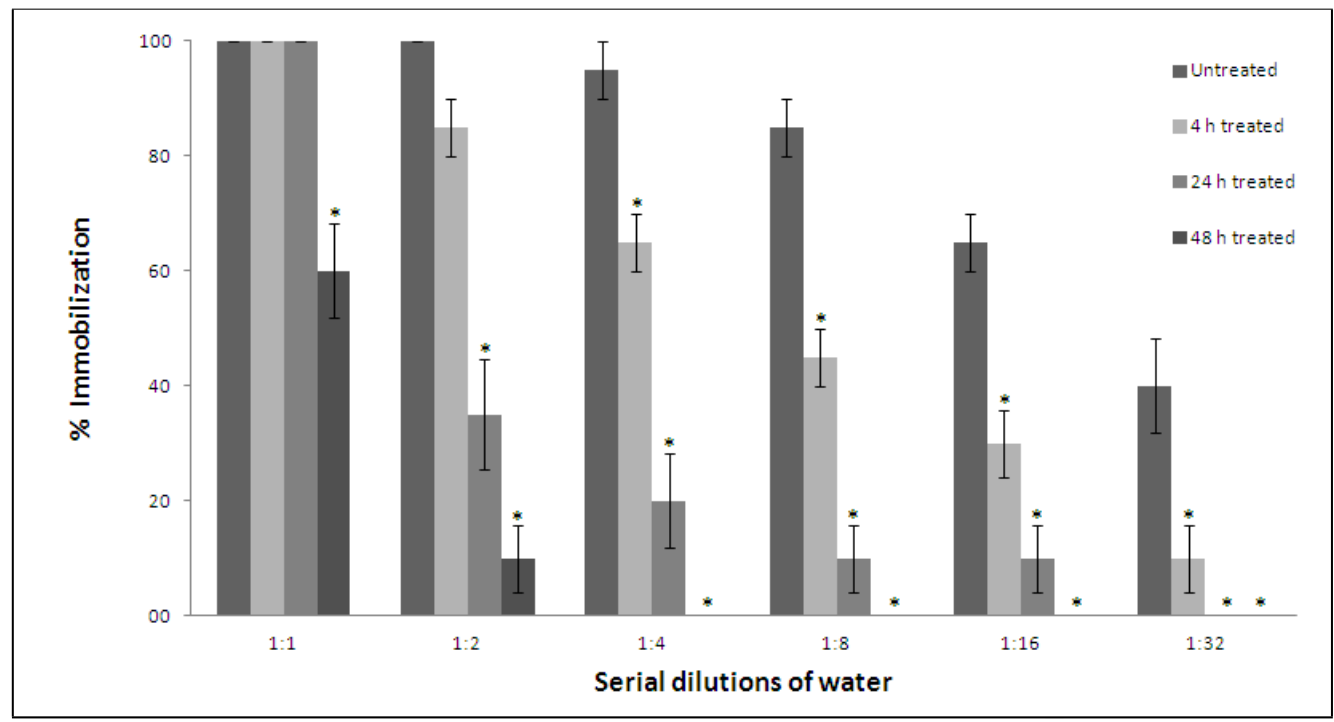

Fig. 6. Evolution of \% immobilization of D. magna bioassays performed during the photocatalyzed oxidation of carbendazim by xanthone at several dilutions.

*: significant differences respect to treatment time $(p<0.05)$ 
<smiles>COC(=O)Nc1nc2ccccc2[nH]1</smiles>

Chart 1. Carbendazim molecular structure 


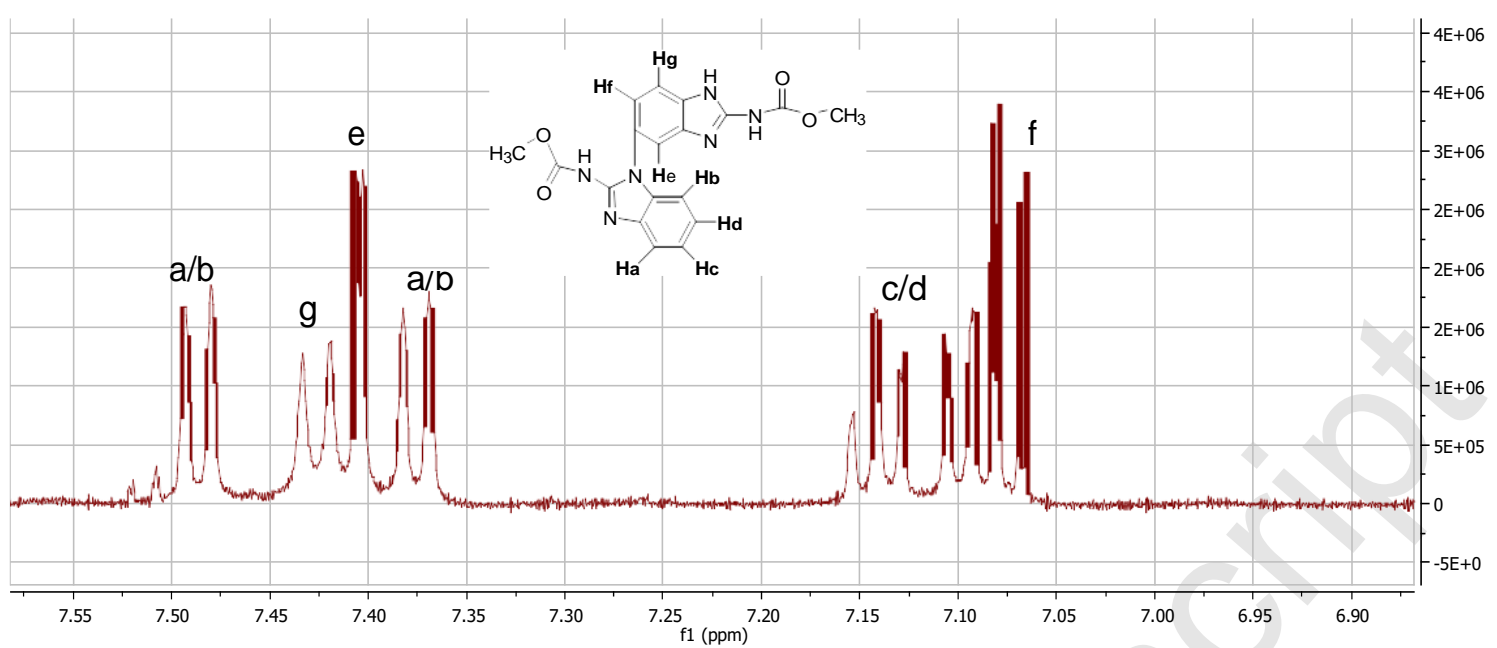

Chart 2. Molecular structure of 2 and correlation between the aromatic hydrogens and the $1 \mathrm{H}$ NMR spectrum. 